\title{
Two cases of pycnodysostosis (the malady of Toulouse-Lautrec)
}

\author{
A. R. L. Clark \\ M.B.B.S.(Lond.) \\ Medical Officer, Bancroft Mines Hospital, Chililabombwe, Zambia
}

Pycnodysostosis is a rare disease. Only thirty-three cases have appeared in the literature since 1923.

The term pycnodysostosis (from the Greek pycnos $=$ dense, dus $=$ defective and stosis $=$ of bone) was coined by Maroteaux \& Lamy in 1962 for an apparent clinical entity which included micromelic dwarfism, increased radiological density of bone, dysplasia of the skull, atrophy of terminal phalanges, straightening of the mandibular angle and, in some cases, dysplasia of the acromial end of the clavicle (Schuler, 1963; Elmore, 1967).

The disease, inherited as an autosomal recessive, occurs in all races and both sexes, and has been diagnosed in varying age-groups from $5 \frac{1}{2}$ months to 43 years.

The distressing features of the disease are the gross deformities and fractures to which the dense brittle bones are especially prone. The fractures, resulting from trivial injuries, tend to occur in the mid-shafts of long bones.

The blood chemistry is not altered and there is no anaemia as the bone marrow is not involved.

Pycnodysostosis was the cause of Toulouse Lautrec's deformities (Maroteaux \& Lamy, 1965).

\section{Case 1}

An African girl, Tabu, had been brought into Bancroft Mines Hospital because, as her mother said: 'She is small for her age'. She was 10 years old, $44 \mathrm{in}$. tall and weighed $50 \mathrm{lb}$. She was intelligent and her physical proportions were normal. Her breasts were developing but she had not menstruated (Fig. 1). She had slight proptosis, epicanthic folds, a receding mandible (the angle of the jaw was not palpable), parietal and frontal bossing and widely dilated coronal-sagittal sutures.

The hands were broad with shortened fingers and spoon-shaped nails (Fig. 2). The vertex-tosymphysis measurement of $22 \frac{1}{2}$ in. almost equalled that of symphysis-to-heel, and her arm-span was $42 \frac{1}{2}$ in. There was no anaemia and no splenomegaly.

She was one of eight children whose ages were 16,

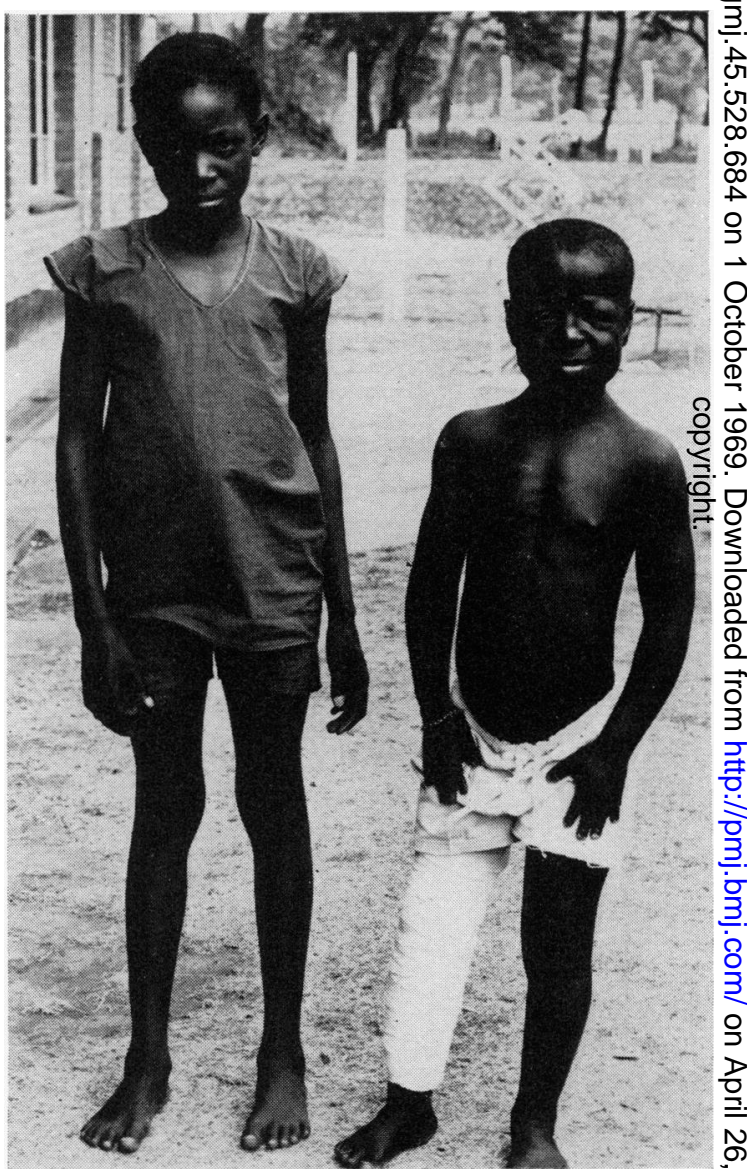

FIG. 1. Tabu with a normal 10-year-old girl.

$13,10,9,6,4,2$ years and 5 months. All the children were of the same parents and six were of normal development but the youngest, a boy, was noted to have a similar facies to Tabu and was later dis- $\stackrel{\mathscr{\Phi}}{\rightarrow}$ covered to have a similar radiological picture (Case 7 2). All the children of the family showed good $\bar{D}$ 


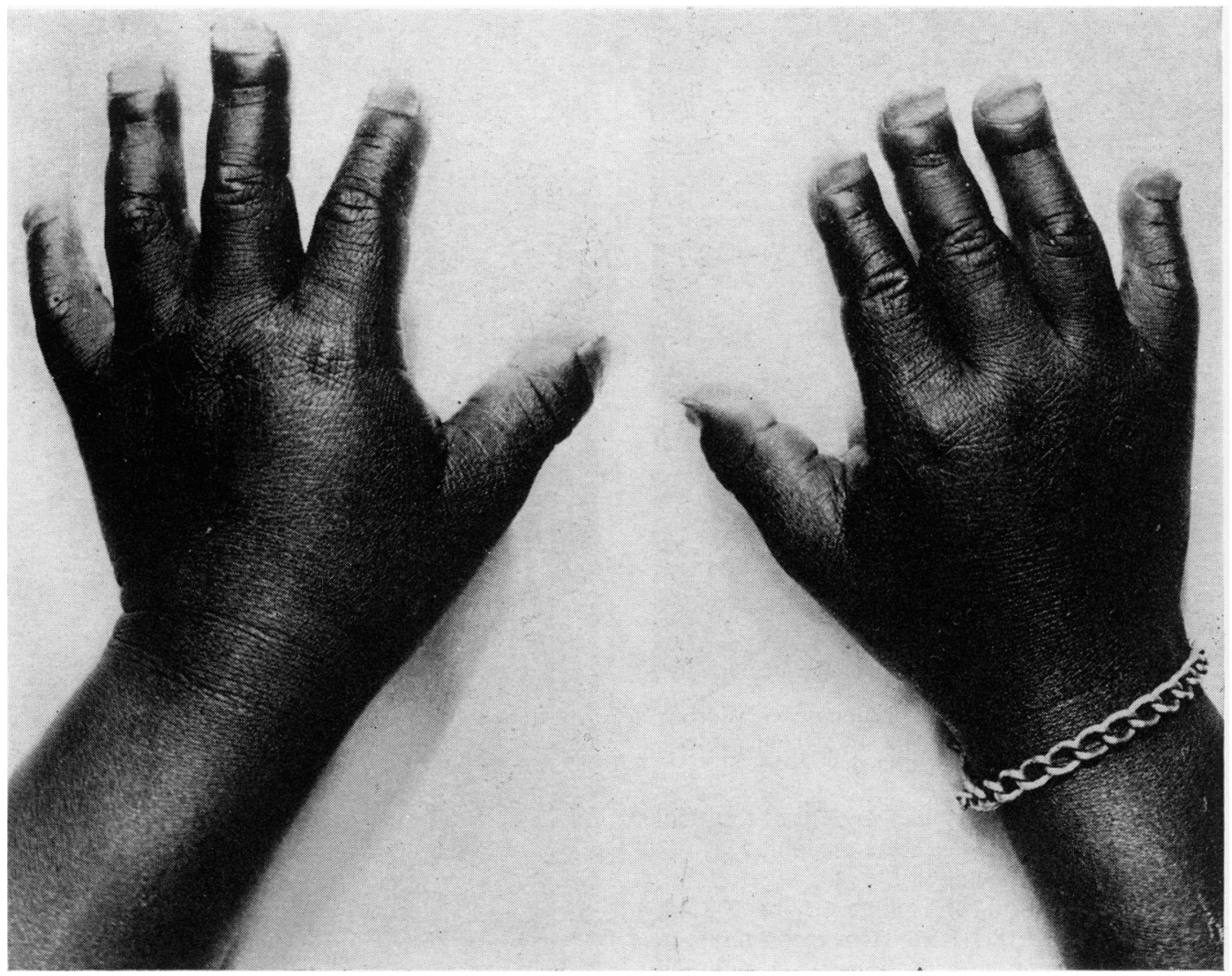

Fig. 2. Photograph showing Tabu's broad hands with shortened fingers and spoon-shaped nails.

average intelligence and Tabu was not retarded, being in the upper stream at her school. The parents were normal and there was no history of consanguinity.

X-ray showed multiple skeletal abnormalities with increased radiographic density but the marrow could still be differentiated. All the skull sutures were widely separated and the ascending ramus and inferior border of the mandible formed a straight line (Fig. 3). The terminal phalanges of the feet and fingers were atrophic (Fig. 4). There was a fracture at the base of the middle metacarpal of the left hand but of this no complaint had been made. The acromial end of the clavicles were hypoplastic. Healed fractures were seen in the mid-shafts of the right femur and left tibia. Lateral views of the vertebrae showed a fish-tail deficiency in the anterior bodies.

Blood chemistry: haemoglobin $11.4 \mathrm{mg} / 100 \mathrm{ml}$, calcium $10.7 \mathrm{mg} / 100 \mathrm{ml}$, phosphate $4.0 \mathrm{mg} / 100 \mathrm{ml}$, alkaline phosphatase $15 \mathrm{King}$ Armstrong units, urea $22 \mathrm{mg} / 100 \mathrm{ml}$, protein bound iodine $6.6 \mathrm{mg} /$ $100 \mathrm{ml}$, cholesterol $290 \mathrm{mg} / 100 \mathrm{ml}$.
It is interesting to note that Tabu was admitted to hospital in 1963 with fractures of the mid-shaft of the right tibia and femur and that serial X-rays showed healing not to be complete until about 2 years later.

Tabu was discharged in September 1968, but was re-admitted 2 weeks later because of a fracture of the mid-shaft of the left tibia following a kick.

\section{Case 2}

This case was discovered when investigating Tabu's family. The child, the youngest of the family, was $5 \frac{1}{2}$ months old.

The striking similarity of facies to Tabu was first noted together with the marked frontal and parietal bossing. The coronal and sagittal sutures were widely separated and the circumference of the skull was $16 \frac{1}{4}$ in. No teeth had erupted and the child was just able to sit up unaided. The liver and spleen were palpable, each being $2 \mathrm{~cm}$ below the costal margin. The radiological picture was similar to that found in Case 1. The bones were dense, there was straighten- 


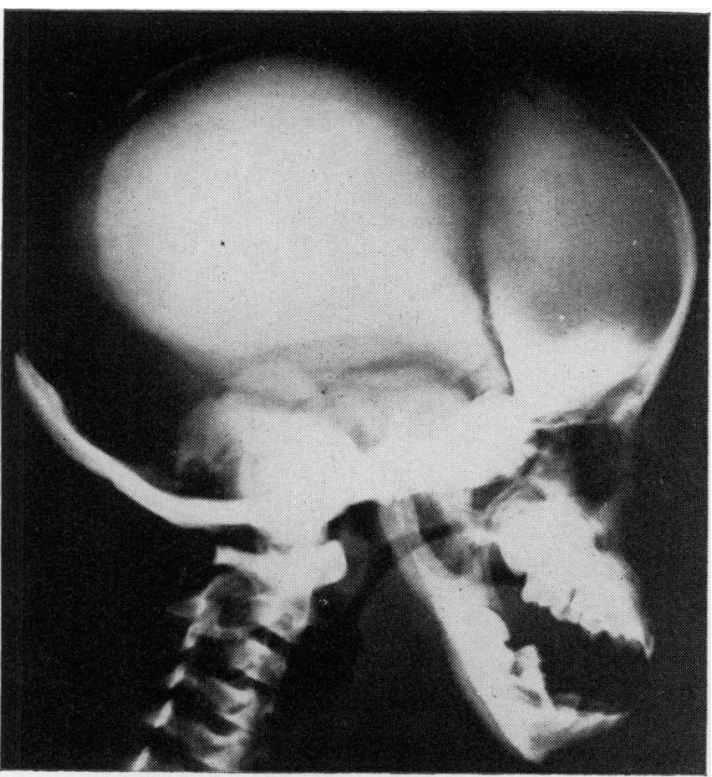

Fig. 3. X-ray of skull. All the skull sutures were widely separated, and the ascending ramus and inferior border of the mandible formed a straight line.

ing of the mandibular angle and the terminal phalanges of toes and fingers were atrophied.

Blood chemistry: haemoglobin $11 \mathrm{mg} / 100 \mathrm{ml}$, calcium $10.4 \mathrm{mg} / 100 \mathrm{ml}$, phosphate $6.1 \mathrm{mg} / 100 \mathrm{ml}$, alkaline phosphatase 18.1 King Armstrong units.

It was difficult to say why the spleen was enlarged in this case. Anaemia was not significant clinically nor was there a positive blood slide for malaria. One might postulate recurrent underlying infection. Two weeks after admission this infant developed an overwhelming respiratory infection and died on the 2 nd day of the illness.

\section{Diagnosis}

The essential features are dwarfism, separated cranial sutures and shortened fingers, supported by an X-ray picture, as already described, in which the bones are dense but the marrow can still be discerned albeit with some difficulty.

\section{Differential diagnosis}

Conditions of dwarfism associated with bony abnormalities are considered but have been listed into two groups dependent upon closure or nonclosure of the cranial sutures. This latter group is the most important in considering the differential diagnosis.

\section{Conditions with closure of cranial sutures}

Achondroplasia in which the limbs are short relative to the trunk. The essential lesion is a lack of

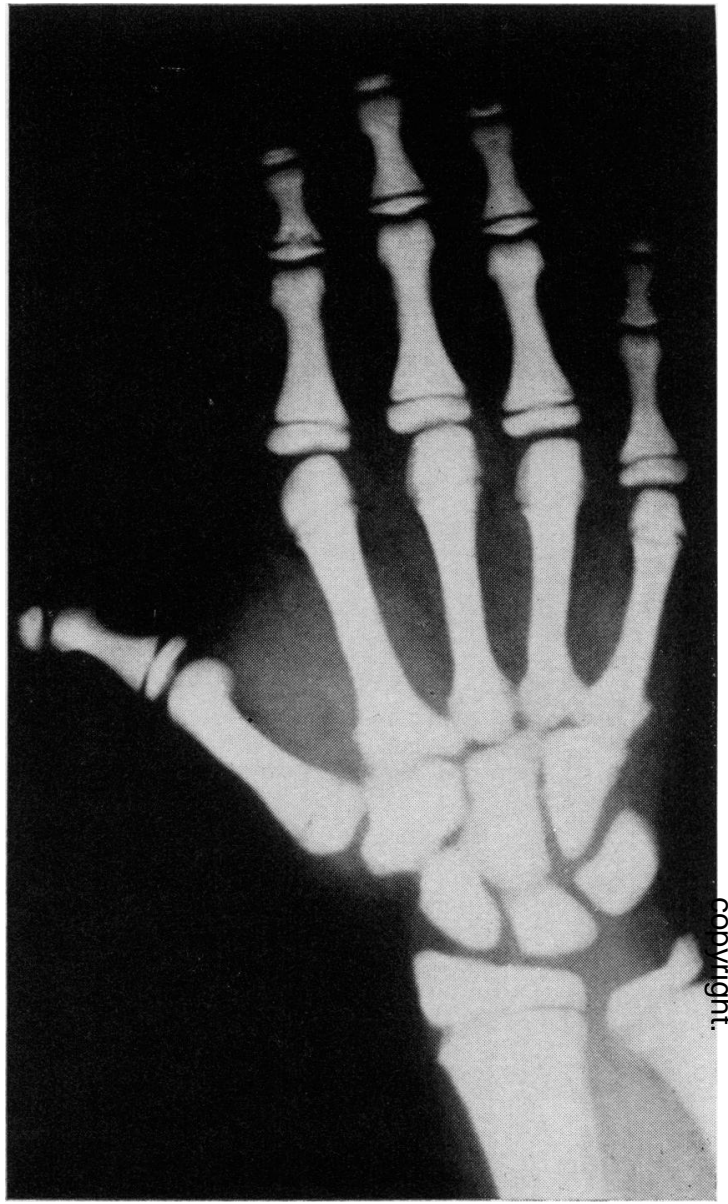

Fig. 4. X-ray of hand showing atrophy of the phalariges.

proliferation of cartilage at the epiphysial plates at the ends of the long bones resulting in short thick bones. Bones such as the skull and clavicle which ossify from membranes are unaffected. The mentality is normal.

Morquio's syndrome in which deformities result from disordered calcification with consequent inability to bear weight. The features of the condition are similar to those of rickets but unlike the latter the blood chemistry is normal. The cornea is cloudy, aortic regurgitation and osteoporosis occur.

Gargoylism: somewhat similar to Morquio's syndrome but there is mental deficiency, clouding of the cornea in some cases, hepatosplenomegaly and skeletal changes resulting from a disturbance of lipoid metabolism, and coronary artery disease.

Rickets in which craniotabes may be found from about the 4th month. Frontal and parietal bossing similar to that found in pycnodysostosis may occur. There is delay in closure of the fontanelle, enlarge- 
ment of the costochondral junctions and thickening of the wrists and ankles. X-ray shows cupping and widening of the distal ends of long bones. The serum alkaline phosphatase is raised and both calcium and phosphorus are diminished (Back \& Cole, 1958; Palmer \& Thomas, 1958).

Cretinism in which there is stunted growth, delay in closure of the fontanelle, large tongue and umbilical hernia. The serum cholesterol is raised and there is anaemia.

\section{Conditions with widely separated cranial sutures}

Osteogenesis imperfecta in which there is diminished radiological density of bones, subject to multiple fractures. The sclerae are sometimes blue. There are two varieties; one intra-uterine in which fractures are much more prone, and a post-natally occurring type, with a better prognosis. Blood chemistry is normal.

Cleidocranial dysostosis. In this the cranial sutures are widely separated and, in addition, the entire clavicle or its middle portion is absent.

Albers-Schonberg disease. The bones are brittle and easily fractured. Haemolytic anaemia occurs, and hepatosplenomegaly and lymph node enlargement owing to extramedullary haematopoiesis. Radiological picture: increased density of bone with obliteration of the bone marrow. In the skull the increased density is especially noted at the base. For further information see Fourman \& Royer (1968).

\section{Acknowledgments}

I wish to thank Dr Levy, Senior Radiologist, University of Witwatersrand, for his report on the X-rays and for making the diagnosis, Dr Glatthaar, Medical Adviser, AngloAmerican Corporation (Zambia), who originally diagnosed osteopetrosis and who sought the opinion of Dr Levy, Mr B. Stocks, United Church of Zambia, who kindly assisted by taking the photographs; finally, Dr V. G. Caiger, Chief Medical Officer, Bancroft Mines Hospital, for his encouragement and helpful criticisms and suggestions and for permission to publish.

\section{References}

BACK, E.H. \& Cole, W.R. (1958) Osteopetrosis associated with rickets and scurvy. Brit. J. Radiol. 31, 709.

Elmore, S.M. (1967) Pycnodysostosis: a review. J. Bone Jt Surg. 49A, 153.

Fourman, P. \& Royer, P. (1968) Calcium Metabolism and the Bone, 2nd edn. Blackwell Scientific Publications, Oxford and Edinburgh.

MaroteauX, P. \& LAMY. M. (1962) Deux observations d'une affection osseuse condensante: la pycnodysotose. Arch. franc. Ped. 19, 267.

MaroteauX, P. \& LAMY, M. (1965) The malady of ToulouseLautrec. J. Amer. med. Ass. 191, 715.

Palmer, P.E.S. \& Thomas, J.E.P. (1958) Osteopetrosis with unusual changes in the skull and digits. Brit. $J$. Radiol. 31, 705.

Schuler, S. (1963) Pycnodysostosis. Arch. Dis. Child. 38, 620.

\title{
Hypermobility of the superior tibio-fibular joints
}

\author{
T. G. J. BRIGHTMORE \\ F.R.C.S.
}

\section{Kingston Hospital, Surrey}

IN NORMAL persons joint mobility varies with age, body-build and race. Joint laxity decreases with age and is often increased in thin individuals, African Negroes, Indians and Pakistanis (Kirk, Ansell \& Bywaters, 1967). Unduly lax joints with a greater range of movement than the accepted normal are termed hypermobile, and this may be temporary or persistent. The former, occurring in the pregnant woman, is due to a uterine hormone causing increased maternal joint laxity (Hisaw, 1926; Wilkinson, 1963), and which, after passing into the foetal circulation (Chapple \& Davidson, 1941) also causes foetal and transient neonatal joint laxity because of its inadequate conjugation by an immature foetal liver (Andrén \& Borglin, 1961). Persistent hypermobility may be congenital or acquired. The acquired type may be compensatory to a contiguous rigid joint, or follow muscle disease, neuropathic joint disease, trauma or inflammatory polyarthritis. Congenital hypermobility has been observed in certain mesenchyme dysplasias producing disproportion in bone and ligament growth rates. These include achondroplasia (Sutro, 1947), osteogenesis imperfecta (Key, 1927), Marfan's syndrome, the Ehlers-Danlos syndrome (McKusick, 1966) and the Achard syndrome (Parish, 1960). It has been noted in the rare metabolic conditions of homocystinuria (Schimke et al., 1965) and hyperlysinaemia (Ghadimi, Binnington \& Pecora, 1965). It is also seen in congenital dislocation of the hip (Lorenz, 1920; Carter \& Wilkinson, 1964) and recurrent dislocation of patella and shoulder (Sutro, 1947; Carter \& Sweetnam, 1960).

Hypermobility also occurs in otherwise normal people, often with a familial incidence (Finkelstein, 1916; Key, 1927; Sutro, 1947; Carter \& Sweetnam, 